\title{
Article \\ Optically Induced Field-Emission Source Based on Aligned Vertical Carbon Nanotube Arrays
}

\author{
Mengjie Li, Qilong Wang, Ji Xu, Jian Zhang, Zhiyang Qi and Xiaobing Zhang * \\ School of Electronic Science and Engineering, Southeast University, Nanjing 210096, China; \\ 230189115@seu.edu.cn (M.L.); northrockwql@seu.edu.cn (Q.W.); xu@seu.edu.cn (J.X.); \\ contact_zhangiian@163.com (J.Z.); qizhiyang2009@163.com (Z.Q.) \\ * Correspondence: bell@seu.edu.cn
}

check for updates

Citation: Li, M.; Wang, Q.; Xu, J.;

Zhang, J.; Qi, Z.; Zhang, X. Optically Induced Field-Emission Source Based on Aligned Vertical Carbon Nanotube Arrays. Nanomaterials 2021, 11, 1810. https://doi.org/10.3390/

nano11071810

Academic Editor: Filippo Giannazzo

Received: 10 June 2021

Accepted: 9 July 2021

Published: 12 July 2021

Publisher's Note: MDPI stays neutral with regard to jurisdictional claims in published maps and institutional affiliations.

\begin{abstract}
Due to the high field enhancement factor and photon-absorption efficiency, carbon nanotubes (CNTs) have been widely used in optically induced field-emission as a cathode. Here, we report vertical carbon nanotube arrays (VCNTAs) that performed as high-density electron sources. A combination of high applied electric field and laser illumination made it possible to modulate the emission with laser pulses. When the bias electric field and laser power density increased, the emission process is sensitive to a power law of the laser intensity, which supports the emission mechanism of optically induced field emission followed by over-the-barrier emission. Furthermore, we determine a polarization dependence that exhibits a cosine behavior, which verifies the high possibility of optically induced field emission.
\end{abstract}

Keywords: photo-electron emission; optically induced field emission; field emission; VCNTAs; photosensitivity

\section{Introduction}

Optically induced field-emission has drawn extensive research attention in nextgeneration ultrafast electron diffractive imaging and spectroscopy [1], compact coherent x-ray sources [2], and attosecond research [3,4]. In the investigation of a hybrid emission regime for ultrafast optically induced field-emission, a compelling trend is the employment of increasingly exotic nanomaterials. This is because the field enhancements stem from the local geometry and the sub-wavelength confinement of the optical field $[5,6]$. The potentially lower work function for such nanomaterials is also a favorable factor that reduces the need for the strong optical field that is normally required [7], and the strong-field photoelectron emission from single metal nanostructures has resolved the transition between multiphoton photoemission and optical field emission [8]. Other work has focused on few-cycle femtosecond (fs) laser pulses acting on a sharp tungsten tip, followed by measuring the energy of the emitted electrons [9]. In general, many works on multiphoton absorbing nanostructures and strong-field emission cathodes focus on single metal tips [8,10-12], a single nanomaterial [5,13-16], and an array of nano-sharp high-aspect-ratio silicon columns [17]. However, the high costs of traditional materials and the difficult fabrication process [18-21], which causes the tip to 'burn out' in a strong field, are barriers to the practicability of their material. Therefore, it is urgent to discover novel kinds of nanomaterial with favorable properties, such as the ability to be prepared in large quantities (using a simple preparation process) and robust electron emission abilities under laser irradiation. Possible nanomaterials that meet these requirements are carbon nanotubes (CNTs) [22-26]. However, when using CNTs with a one-dimensional morphology as an electron source, the inherent strong exciton resonance and high thermal conductivity may result in a high damage threshold [27-34]. Compared with low work-function materials [35-37], CNTs show excellent photon absorption efficiency [38,39]. However, a thorough exploration of the femtosecond laser-induced field-emission mechanism based 
on CNTs arrays is lacking. Besides, combining the advantages of CNTs arrays for field emission with optically induced field-emission, we can investigate the optimum conditions of emission that ensure highly monochromatic ultrafast laser-triggered electron emission, thereby improving its practical value as an electron source.

In this paper, vertical carbon nanotubes arrays (VCNTAs) were used as the emitting cathode. The cathodes exhibited low turn-on field $(1.2 \mathrm{~V} / \mu \mathrm{m})$ and $2 \%$ fluctuation of emission stability. It is also noteworthy that the emission current was strongly dependent on the polarization angle of the incident laser, which exhibited an obvious cosine behavior, verifying that optical field emission rather than thermal-induced emission was occurring. The experimental results clearly showed the three electron emission processes for the VCNTAs with laser irradiation. Therefore, the VCNTAs generate high-throughput electron beams and they show significant light sensitivity to the ultrafast laser.

\section{Experimental}

The VCNTAs were fabricated by the chemical vapor deposition (CVD) technique [40] on a commercial highly doped silicon substrate (n-type, the RDMICRO in Suzhou) with a conductivity of $0.003 \Omega \cdot \mathrm{cm}$. First, the substrate was patterned using SPR220-7.0 UV resist and an MA6 ultraviolet lithography device. Then, the patterned substrates were used to sequentially deposit aluminum $(20 \mathrm{~nm})$ and Fe $(10 \mathrm{~nm})$ catalyst layers via magnetron sputtering. Finally, the substrates were placed into a quartz tube reactor (length of $120 \mathrm{~mm}$, inner diameter of $100 \mathrm{~mm}$ ) and mixed argon (Ar, 99\%, $100 \mathrm{sccm}$ ) in a tube furnace. Thje furnace was heated to $700{ }^{\circ} \mathrm{C}$ and methane $\left(\mathrm{CH}_{4}, 99 \% 200 \mathrm{sccm}\right)$ and hydrogen $\left(\mathrm{H}_{2}, 95 \%\right.$, $200 \mathrm{sccm}$ ) were passed through the tube reactor for $10 \mathrm{~min}$ at a pressure of $4000 \mathrm{~Pa}$, followed by cooling the CVD system in Ar to room temperature. The side and top views of the fabricated VCNTAs were observed via a (Quanta 200 FEI) scanning electron microscope (SEM) images of which are shown in Figure 1a,b. The multiple-walled CNTs in the array are uniform, dense, well-aligned, and perpendicular to the substrate. The CNTs have diameters of $\sim 30 \mathrm{~nm}$ and dimensions characteristic of a VCNTA $\left(\mathrm{L}_{1}=\mathrm{L}_{2}=20 \mu \mathrm{m}, \mathrm{H}=43 \mu \mathrm{m}\right)$. An image of these, as seen by a (JEOL-2010F) transmission electron microscope (TEM), is presented in Figure 1c. This image shows the characteristics of the lattice fringe. A typical He \& I ultraviolet photoelectron spectrum (UPA, an ESCALAB 250Xi electron spectrometer (Thermo Fisher Scientific, Waltham, MA, USA)) in the binding energy scale is shown in Figure $1 \mathrm{~d}$ for the CNTs. The composition analysis was performed by energy-dispersive X-ray analysis (EDS). A sample of the VCNTAs was confirmed by EDS analysis (Figure 1e), which exhibited the expected signal peaks of $\mathrm{C}$ and $\mathrm{Si}$.

The experimental setup needed a high vacuum environment and a relevant light path. The test sample consisted of a cathode base, a sheet metal anode, and a ceramic gasket that separated the cathode from the anode. The cathode was positioned about $0.2 \mathrm{~mm}$ away from the anode, which had a $1 \mathrm{~mm}$ diameter hole (as shown on the right-hand side of Figure 2). Then the test setup was connected to a high vacuum of $4 \times 10^{-6} \mathrm{~Pa}$. A Keithley 6487 source measurement unit was used to apply bias voltages and collect the emission current. To ensure measurement of the optical-driven electron field emission, we built the light path, as shown on the left side of Figure 2. The VCNTAs are front illuminated by a $150 \mathrm{fs} / 1000 \mathrm{~Hz}$ fs-laser of a central wavelength of $650 \mathrm{~nm}$ with the laser excitation power varied using a variable attenuator from approximately $0 \mathrm{~mW}$ to $90 \mathrm{~mW}$. A laser power meter (Spectra-Physics 407A) was used to measure and calibrate the laser power, and the power density range of the mono-pulse was determined. The laser was directly injected into the cathode through a quartz window. The power density ranged from 0 to $0.306 \mathrm{TW} / \mathrm{cm}^{2}$, which was calculated from the following formula for laser power:

$$
P_{0}=\frac{\frac{U_{\text {laser }}}{f}}{t} \times \frac{1}{S}
$$


where $U_{\text {laser }}$ is the laser energy, $f$ is the laser frequency, $S$ is the surface area of the laser beam and $t$ is irradiation time. The laser was focused on a light spot with a diameter of $1 \mathrm{~mm}$ on the VCNTAs.
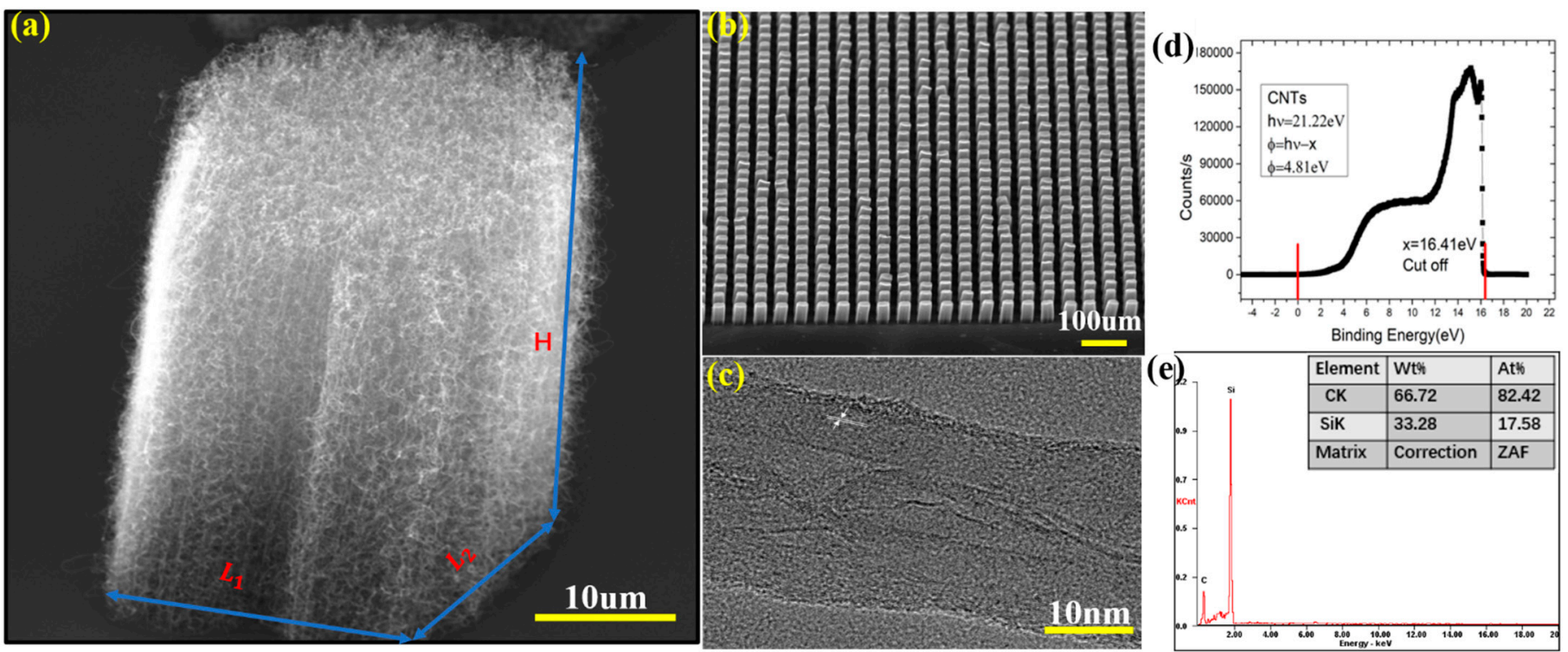

Figure 1. SEM images of (a) a cluster of nanotubes, and (b) a top view of the aligned CNT-array sample, (c) (HR)TEM images of the single CNT, (d) A work function of $4.81 \mathrm{eV}$ is determined from the secondary emission onset in ultraviolet photoelectron spectroscopy, (e) EDS test of the aligned CNT-arrays sample.

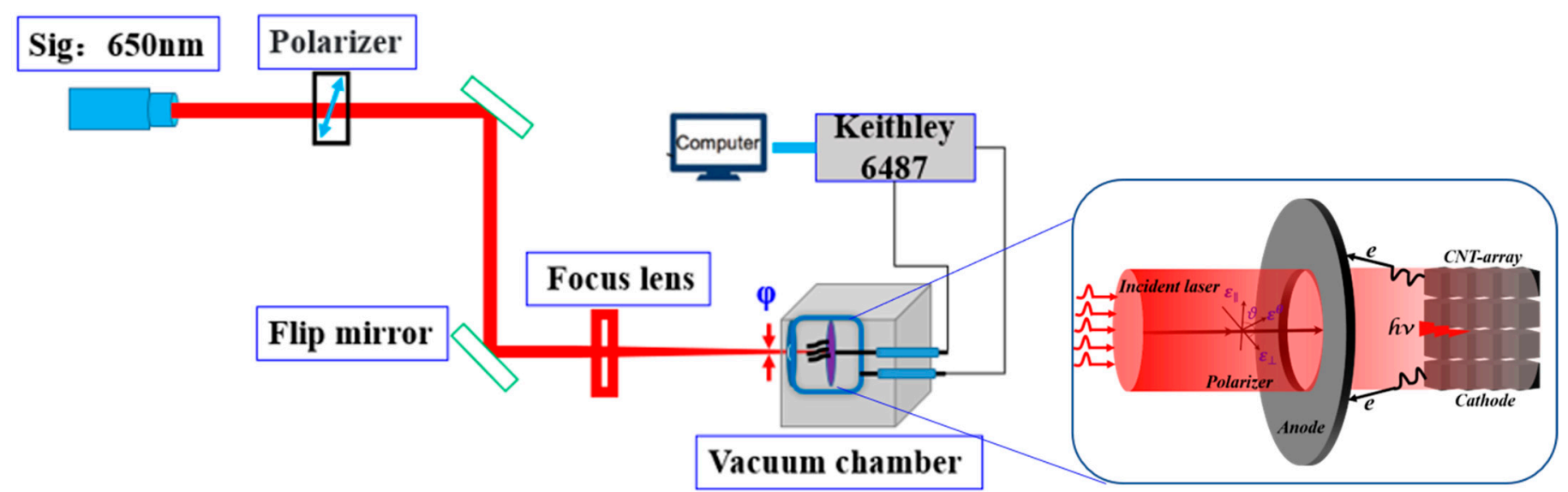

Figure 2. A schematic of photoemission configuration.

\section{Results and Discussion}

In order to investigate the optically induced field-emission characteristics, J-E curves were analyzed by using the different laser powers as shown in Figure 3a,b. We observed a rapid rise of the photocurrent at a lower bias $(<20 \mathrm{~V})$ due to the space-charge effect in which the photons and the ionized electrons form an electron cloud distribution around the cathode, which is attracted to the anode as the bias increases [41]. The electron emission properties of the VCNTAs were highly dependent on both the laser power and the bias voltage. At an electric field of $1.43 \mathrm{~V} / \mu \mathrm{m}$, the VCNTAs obtained an emission current of $\sim 1 \mu \mathrm{A} / \mathrm{cm}^{2}$ without laser irradiation. This electric field is regarded as turn on field. When the input laser power was increased to $45 \mathrm{~mW}$, the turn on electric field of the VCNTAs decreased to $1.2 \mathrm{~V} / \mu \mathrm{m}$. The turn-on voltage of the VCNTAs was $1.28 \mathrm{~V} / \mu \mathrm{m}$ at the laser powers up to $90 \mathrm{~mW}$. This is because the strong light field effects dominate the 
vacuum barrier, and the multiphoton light emission channel becomes saturated at a higher intensity [6]. Moreover, we measured the emitter-current as a function of the bias-voltage when the laser power was switched from 0 to $90 \mathrm{~mW}$. In both cases, the data fits into the Fowler-Nordheim equation [42], in which $J$ is related to the tunnel current density, $F$ is the local hybrid field strength, and $\phi$ is the effective work function:

$$
\begin{gathered}
J=\frac{e^{3} F^{2}}{8 \pi h \phi t^{2}(\omega)} E\left[\frac{8 \pi \sqrt{2 m} \phi^{\frac{3}{2}}}{3 h e F} v(\omega)\right] \\
I=2 \pi R^{2} J
\end{gathered}
$$

where $I$ is the emitter current, $R$ is the radius of the cathode emitter area, and $F$ is the composite field, which is composed of the electric field and optical wave field. Then, the field enhancement factor $(\beta)$ of CNTs can be calculated from the slope $(S)$ of the linearized F-N data, using the transformed to Equations (2) and (3).

$$
\begin{gathered}
\ln \left(\frac{I}{V^{2}}\right)=-\frac{b \phi^{\frac{3}{2}} d}{\beta}\left(\frac{1}{V}\right)+\ln \left(\frac{A a \beta^{2}}{\phi d^{2}}\right) \\
s=\frac{-b \phi^{\frac{3}{2}} d}{\beta}
\end{gathered}
$$

where $\Phi$ is the work function, $d$ is the distance between cathode and anode, $a=1.56 \times 10^{-6}$, $b=6.83 \times 10^{7}$. Taking the lowest turn-on field as the critical boundary surface, it divides the electric field into two parts as shown in Figure $3 \mathrm{~b}$. Combined with the calculation of Formula (5), the values of s were 19.23 (no-laser), $18.96(14 \mathrm{~mW}), 20.54(45 \mathrm{~mW})$, and 21.69 $(90 \mathrm{~mW})$. It was shown that the different laser powers have a weak influence on the field enhancement factor and proves that the electron emission mechanism is in total accordance with the formula F-N [43] under the high electric field. Moreover, the conclusion also indicates that the main mechanism of the electron emission is field emission under the high electric field.

Further supporting evidence for the optically induced field-emission is provided by the input light polarization dependence of the photocurrent as shown in Figure 3c. Using a polarizing plate, the incident laser polarization angle was varied between the angles of $0^{\circ}$ and $360^{\circ}$, which clearly showed that the emission current has a polarization dependence. This curve also largely excludes the possibility of a thermally induced field emission [10]. Thus, we can infer that electron emission is rapid on the input of the laser pulse, and the possibility of any thermal emission mechanisms associated with laser-induced heating of the tip can be ruled out [44]. For a bias voltage of $300 \mathrm{~V}$, there is more than $\sim 90 \%$ chance that the emitted electrons derive from the optical input field. When excited by the ultrafast laser pulses, electrons may be excited to nonequilibrium states by obtaining energy from both photons and thermal (laser-heating) effects. In the case of photon-driven excitation, the time scale of the general electron pulse is the same as that of the laser pulse [45]. In the case of thermally driven excitation, time frames of $>100 \mathrm{fs}$ are required to transfer sufficient thermal energy to the local electron population.

To obtain the relationship between the electron emission and the input laser power, which is mainly laser-induced when below the turn-on voltage, the following uses the Fowler-DuBridge model [46] in which the traces are fit with a polynomial:

$$
I=\sum C_{n} P^{n}
$$

where $n$ is the order of the photon process, $\mathrm{P}$ is the average laser power, and $C_{n}$ is a fitting parameter. Figure $3 \mathrm{~d}$ shows, at a bias voltage of $300 \mathrm{~V}$, the electron photoemission currents as a function of the laser intensities. At $0-45 \mathrm{~mW}$ we obtained $n=0.599$ and at $45-90 \mathrm{~mW}$ $n=0.2979$, which are illustrated by the red and blue dashed lines (intentionally offset for 
clarity in the log-log scale) in Figure 3d. We observed continuous transitions between power laws of different orders. Beyond $45 \mathrm{~mW}$, the slope of the current becomes smaller. This is because the multiphoton emission channel is saturated at a higher intensity. In such cases, the strong light field effects dominate the vacuum barrier [41].

(a)

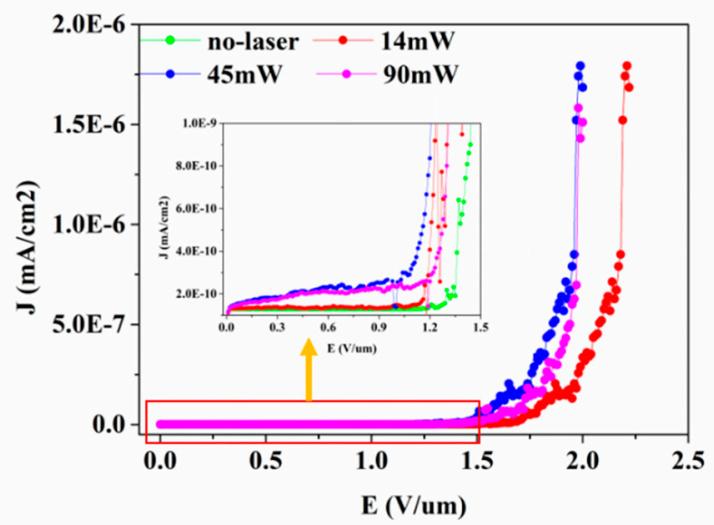

(c)

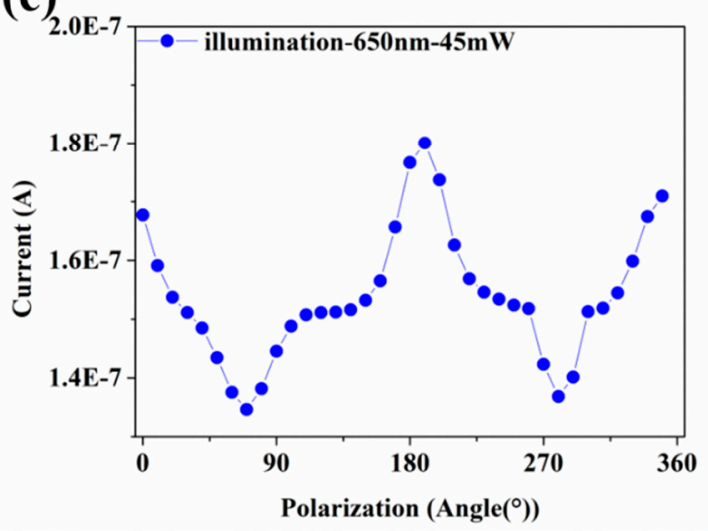

(b)

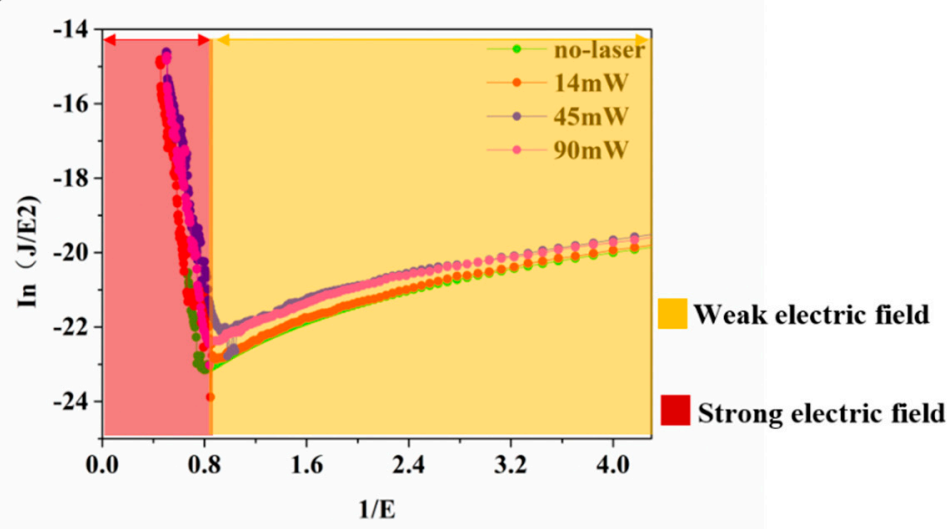

(d)

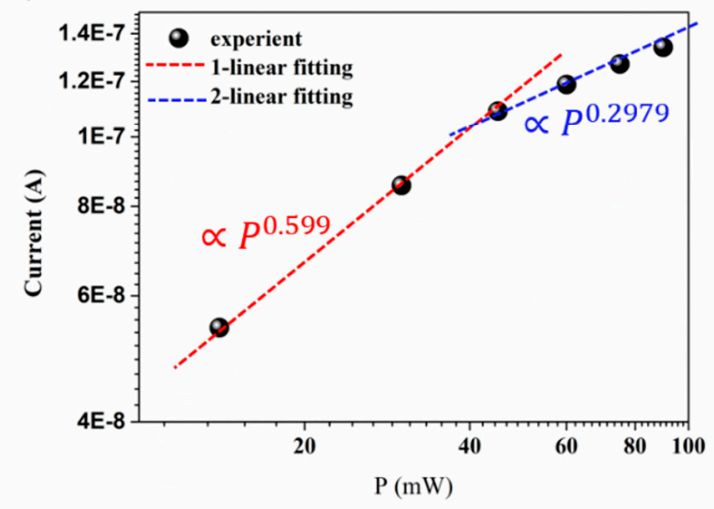

Figure 3. (a) J-E curves for an excitation laser wavelength of $650 \mathrm{~nm}$ at selected average values of the input laser power. The inset is enlarged for the y-axis values between 0 to $\sim 1 \times 10^{-9} \mathrm{~mA} / \mathrm{cm}^{2}$; (b) The Fowler-Nordheim (F-N) plots. (c), Photocurrent curves dependent on the incident light polarization, given at a $300 \mathrm{~V}$ bias voltage and the $14 \mathrm{~mW}$ laser power for $650 \mathrm{~nm}$ excitation. (d) I-P curves at selected bias voltages for $650 \mathrm{~nm}$ excitation. The dotted lines represent the fitting curves.

A hybrid emission regime for strong-field above-threshold photoemission has been widely studied [7], but the process for femtosecond laser-assisted field-emission with varying input electric fields has lacked a thorough exploration [26]. It has been shown that VCNTAs can operate via three processes as the electric field increased $[9,47,48]$, (a) photoelectron emission, (b) optical induced field emission, and (c) field emission. Under these regimes, electrons are first excited from their original energy level to a higher energy-level state by absorbing thermal or photon energy. Then, they face a much narrower tunneling barrier, meaning that the tunneling probability is greatly increased, which results in a highly enhanced emission current.

The relationship between emission current and the illumination time in the bias voltage range from $100 \mathrm{~V}$ to $400 \mathrm{~V}$ and the laser power range from 0 to $90 \mathrm{~mW}$ is as follows: The current fluctuation depends on the laser power when the bias voltage is less than $300 \mathrm{~V}$ as exhibited in Figure 5a,b. In such conditions, the active process is photo-electron emission, as shown in Figure 4a, which involves excitation of the surface of the VCNTAs by a large number of photons, so that electrons overcome the vacuum barrier inside the material. When the bias voltage is increased, the vacuum barrier is compressed and the electrons inside the material can escape more easily from the energy barrier. The fluctuating current 
here is quite remarkable since a lot of active electrons can tunnel out of the material with a strong photo-electric field [44]. The process is the optically induced field-emission shown in Figure $4 \mathrm{~b}$. In this situation, the electrons are excited by the laser into an intermediate state, and the electrons can then tunnel into the vacuum via the potential barrier at the tip of the material that is compressed by the applied DC voltage. As shown in Figure $5 c$, the current fluctuations still exist, which is related to the optical modulation with the bias voltage at $1.5 \mathrm{~V} / \mu \mathrm{m}$. Simultaneously, the maximum value of the emission current is $6.57 \times 10^{-7} \mathrm{~A}$ for a laser power of $45 \mathrm{~mW}$, which is more than 13 times the current without the irradiation condition at the same bias voltage. Finally, when the bias voltage is high enough, the energy barrier is compressed which allows the electrons to tunnel to the vacuum. By comparing the results of Figure $5 c$, the fluctuations in the current reflect the dominant effects of the electric field and optical field on the electric emission of the carbon nanotubes [49]; in these cases, the optical field instantaneously fluctuates the energy barrier [50]. When the bias voltage is up to $400 \mathrm{~V}$, the photo-current is almost nonexistent, as shown in Figure 5d. Here, the bias voltage is too high, the energy barrier is completely compressed, so that the electrons can freely tunnel to the vacuum. It is also shown that electron emission from the carbon nanotubes has three progressive pathways via optical and electronic fields.

(a)

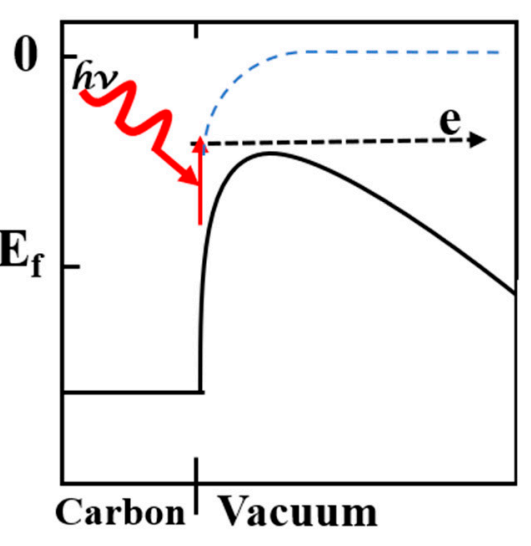

(b)

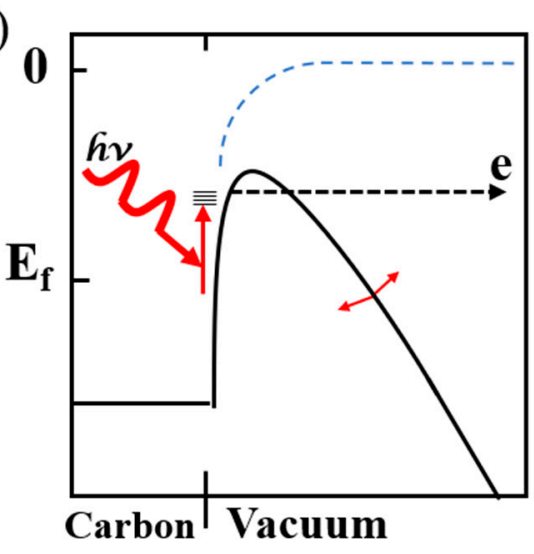

(c)

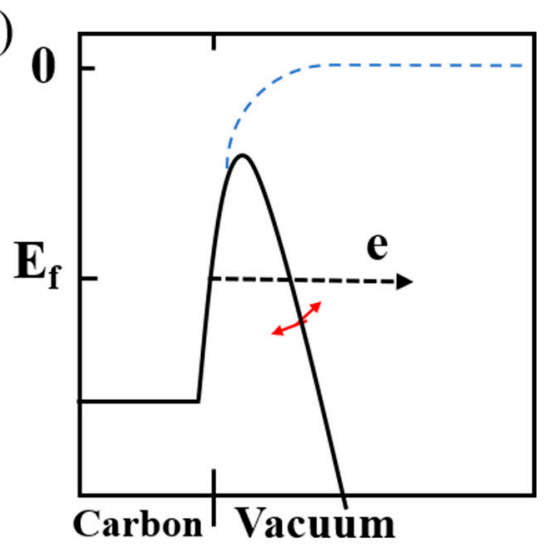

Figure 4. Energy diagrams for (a) photo-electron emission, (b) optically induced field emission, and (c) field emission.

The stability test is shown in Figure 6a. For a bias voltage of $300 \mathrm{~V}$ and a laser power of $45 \mathrm{~mW}$, the emission current was $2.3 \times 10^{-7} \mathrm{~A}$ and the emission variability of the cathode of VCNTs was less than $2 \%$ during the $2400 \mathrm{~s}$. With the irradiation time prolonged, the emission current appeared to fluctuate increasingly, the current fluctuations were extended further (the average current increased). The light excitation was stopped at $1200 \mathrm{~s}$, as shown in Figure 6c. This is because the fs-laser peak power density is too high and the cathode could be ruined in these circumstances. Combined with the SEM image of the cathode surface showing its deformation, as shown in Figure 6d,e, the top of the carbon nanotubes array may show traces of break up. 
(a)

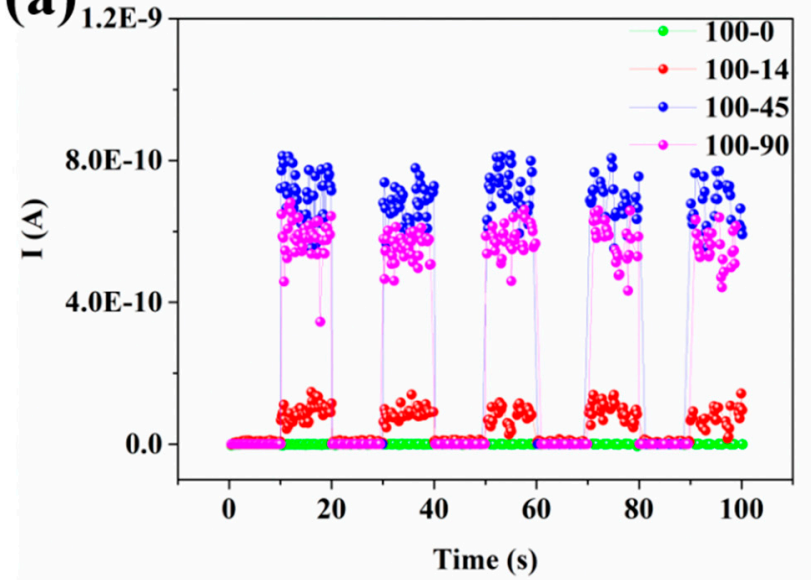

(c)

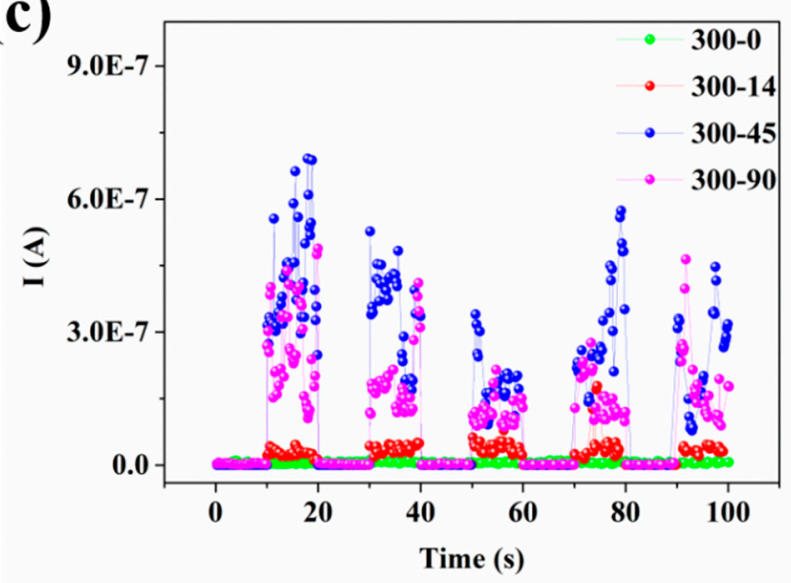

(b)

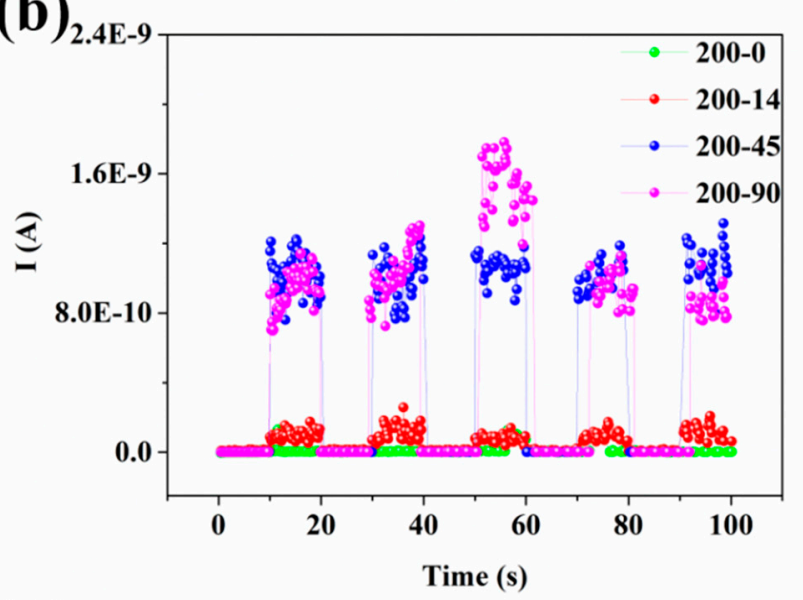

(d)

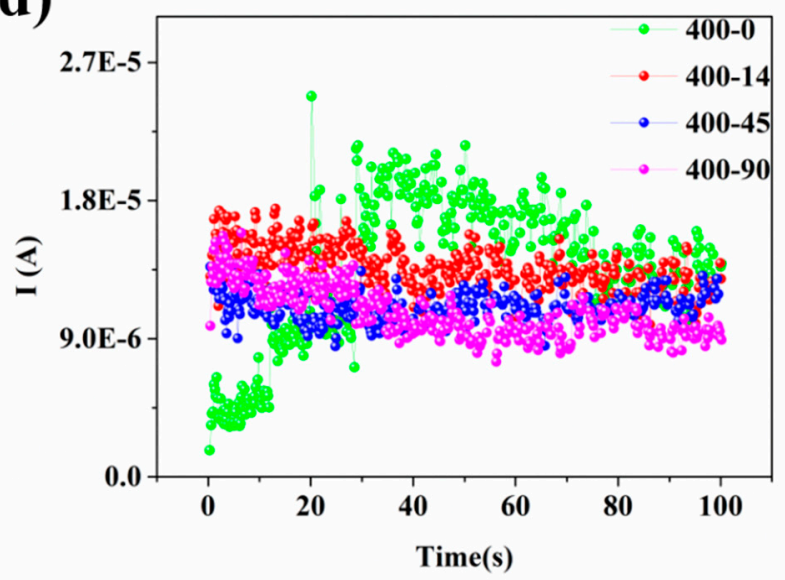

Figure 5. The variation of emission current of the VCNTAs under the different laser power and bias voltage, when the laser is switched on and off. Different colors in each figure represent different excitation laser power, (a) at a bias of $100 \mathrm{~V}$, (b) at a bias of $200 \mathrm{~V},(\mathbf{c})$ at a bias of $300 \mathrm{~V}$, and (d) at a bias of $400 \mathrm{~V}$.

(b)

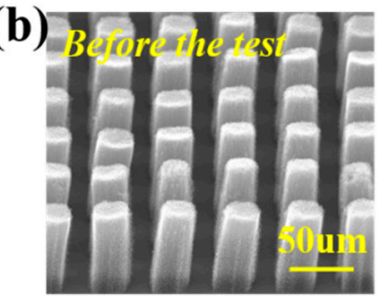

(c)

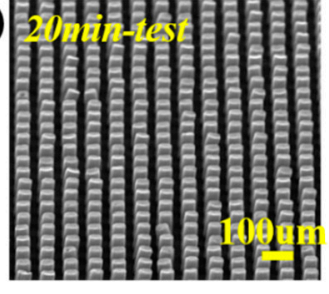

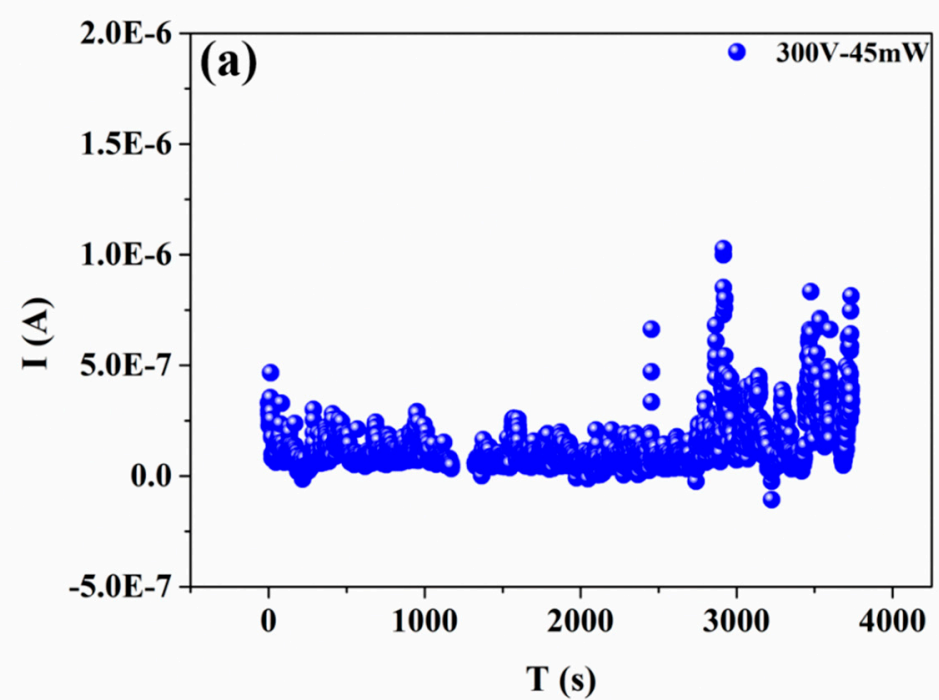

(d)

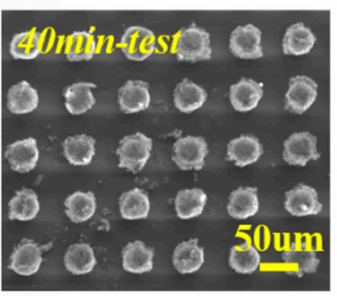

(e)

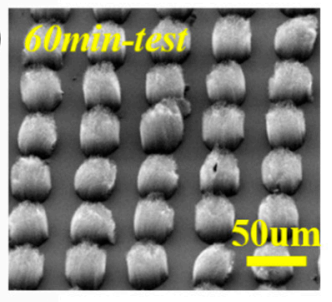

Figure 6. The stability of electron emission, (a) the fluctuation of emission current with the period time. The morphology of VCNTs (b) before the test, (c) after being irradiated for $20 \mathrm{~min}$, (d) after being irradiated for $40 \mathrm{~min}$, and (e) after being irradiated for $60 \mathrm{~min}$. 


\section{Conclusions}

To summarize, vertical carbon nanotubes, acting as emission cathode, can generate high-throughput electron beams with high photosensitivity under the irradiation of an ultrafast laser. The vertical carbon nanotubes arrays (VCNTAs) were used as the cathode for optical field emission, in combination with a high applied electric field and laser illumination, allowing us to modulate the electron emission with a fs-pulse laser. The cathodes exhibited a current of $6.57 \times 10^{-7} \mathrm{~A}$ at $1.2 \mathrm{~V} / \mu \mathrm{m}$, with a $2 \%$ fluctuation of the electron emission. The VCNTAs generate high-throughput electron beams and they exhibit significant light sensitivity to the ultrafast laser. It is possible that they may find applications in high-brightness electron beam technology and ultra-fast imaging.

Author Contributions: Conceptualization, X.Z., M.L., and Q.W.; methodology, M.L.; validation, J.X., J.Z., and Z.Q.; formal analysis, X.Z., M.L., and Q.W.; investigation, M.L.; resources, X.Z. and Q.W.; writing—original draft preparation, M.L.; writing—review and editing, M.L.; supervision, X.Z. and Q.W. All authors have read and agreed to the published version of the manuscript.

Funding: This work was supported in part by the National Science Foundation Project of China (61971133), the Key Laboratory Foundation Project (61428030305), and the Postgraduate Research \& Practice Innovation Program of Jiangsu Province (KYCX17_0095).

Institutional Review Board Statement: The study did not involve humans or animals.

Informed Consent Statement: Not applicable.

Data Availability Statement: Data are contained within the article.

Acknowledgments: The authors thank Chunxiang Xu Team from the optical lab of the State Key Laboratory of Bioelectronics, School of Biological Sciences \& Medical Engineering, Southeast University.

Conflicts of Interest: The authors declare no conflict of interest.

\section{References}

1. Vanacore, G.M.; Fitzpatrick, A.W.P.; Zewail, A.H. Four-dimensional electron microscopy: Ultrafast imaging, diffraction and spectroscopy in materials science and biology. Nano Today 2016, 11, 228-249. [CrossRef]

2. Freund, H.P.; Nguyen, D.C.; Carlsten, B. Three-dimensional analysis of prebunched electron beams in an x-ray free-electron laser. Phys. Rev. Spec. Top. Accel. Beams 2012, 15, 030704. [CrossRef]

3. Gruson, V.; Barreau, L.; Jiménez-Galan, Á.; Risoud, F.; Caillat, J.; Maquet, A.; Carré, B.; Lepetit, F.; Hergott, J.-F.; Ruchon, T.; et al. Attosecond dynamics through a Fano resonance Monitoring the birth of a photoelectron. Science 2016, 354, 734-738. [CrossRef]

4. Graves, W.S.; Kartner, F.X.; Moncton, D.E.; Piot, P. Intense superradiant x rays from a compact source using a nanocathode array and emittance exchange. Phys. Rev. Lett. 2012, 108, 263904. [CrossRef] [PubMed]

5. Herink, G.; Solli, D.R.; Gulde, M.; Ropers, C. Field-driven photoemission from nanostructures quenches the quiver motion. Nature 2012, 483, 190-193. [CrossRef]

6. Kruger, M.; Schenk, M.; Hommelhoff, P. Attosecond control of electrons emitted from a nanoscale metal tip. Nature 2011, 475, 78-81. [CrossRef] [PubMed]

7. Kasmi, L.; Kreier, D.; Bradler, M.; Riedle, E.; Baum, P. Femtosecond single-electron pulses generated by two-photon photoemission close to the work function. New J. Phys. 2015, 17, 033008. [CrossRef]

8. Bormann, R.; Gulde, M.; Weismann, A.; Yalunin, S.V.; Ropers, C. Tip-enhanced strong-field photoemission. Phys. Rev. Lett. 2010, 105, 147601. [CrossRef]

9. Schenk, M.; Kruger, M.; Hommelhoff, P. Strong-field above-threshold photoemission from sharp metal tips. Phys. Rev. Lett. 2010, 105, 257601. [CrossRef]

10. Feist, A.; Echternkamp, K.E.; Schauss, J.; Yalunin, S.V.; Schafer, S.; Ropers, C. Quantum coherent optical phase modulation in an ultrafast transmission electron microscope. Nature 2015, 521, 200-203. [CrossRef]

11. Piglosiewicz, B.; Schmidt, S.; Park, D.J.; Vogelsang, J.; Groß, P.; Manzoni, C.; Farinello, P.; Cerullo, G.; Lienau, C. Carrier-envelope phase effects on the strong-field photoemission of electrons from metallic nanostructures. Nat. Photonics 2013, 8, 37-42. [CrossRef]

12. Kealhofer, C.; Schneider, W.; Ehberger, D.; Ryabov, A.; Krausz, F.; Baum, P. All-optical control and metrology of electron pulses. Science 2016, 352, 429-433. [CrossRef] [PubMed]

13. Li, Z.; Bai, B.; Li, C.; Dai, Q. Efficient photo-thermionic emission from carbon nanotube arrays. Carbon 2016, 96, 641-646. [CrossRef]

14. Chen, J.; Yang, B.; Liu, X.; Yang, J.; Cui, L.; Yan, X. Large field emission current and density from robust carbon nanotube cathodes for continuous and pulsed electron sources. Sci. China Mater. 2017, 60, 335-342. [CrossRef] 
15. Chen, J.; Yang, B.; Lim, Y.D.; Su, L.; Yang, J.; Guo, R.; Tay, B.K.; Yan, X. Field emission cathode based on three-dimensional framework carbon and its operation under the driving of a triboelectric nanogenerator. Nano Energy 2018, 49, 308-315. [CrossRef]

16. Swanwick, M.E.; Keathley, P.D.; Fallahi, A.; Krogen, P.R.; Laurent, G.; Moses, J.; Kartner, F.X.; Velasquez-Garcia, L.F. Nanostructured ultrafast silicon-tip optical field-emitter arrays. Nano Lett. 2014, 14, 5035-5043. [CrossRef]

17. Velasquez-Garcia, L.F.; Guerrera, S.A.; Niu, Y.; Akinwande, A.I. Uniform High-Current Cathodes Using Massive Arrays of Si Field Emitters Individually Controlled by Vertical Si Ungated FETs-Part 2: Device Fabrication and Characterization. IEEE Trans. Electron. Devices 2011, 58, 1783-1791. [CrossRef]

18. Nagao, M.; Yasumuro, C.; Taniguchi, M.; Itoh, S.; Kanemaru, S.; Itoh, J. Field emitter array with a memory function for ultrahigh luminance field. J. Vac. Sci. Technol. B 2007, 25, 464-468. [CrossRef]

19. Yaghoobi, P.; Moghaddam, M.V.; Michan, M.; Nojeh, A. Visible-light induced electron emission from carbon nanotube forests. J. Vac. Sci. Technol. B 2011, 29, 02B104. [CrossRef]

20. She, J.C.; Xu, N.S.; Deng, S.Z.; Chen, J.; Bishop, H.; Huq, S.E.; Wang, L.; Zhong, D.Y.; Wang, E.G. Vacuum breakdown of carbon-nanotube field emitters on a silicon tip. Appl. Phys. Lett. 2003, 83, 2671-2673. [CrossRef]

21. Hendrix, R.; Deibel, J.A.; Fairchild, S.B.; Maruyama, B.; Urbas, A.; Walker, M.; Brown, D. Laser Assisted Electron Emission from Free Standing Carbon Nanotube Paper. In CLEO: Applications and Technology; Optical Society of America: Washington, DC, USA, 2015; p. JW2A.53.

22. Elezzabi, A.Y.; Betz, M.; Green, M.E.; Urbas, A.M.; Her, T.-H.; Kono, J.; Pasquali, M.; Gengler, J.J.; Headrick, R.J.; Bas, D.A. Laser-assisted field emission in single-walled carbon nanotubes. In Ultrafast Phenomena and Nanophotonics XXII; SPIE OPTO: Bellingham, DC, USA, 2018; p. 37.

23. Li, Z.; Yang, X.; He, F.; Bai, B.; Zhou, H.; Li, C.; Dai, Q. High current field emission from individual non-linear resistor ballasted carbon nanotube cluster array. Carbon 2015, 89, 1-7. [CrossRef]

24. Javey, A.; Guo, J.; Wang, Q.; Lundstrom, M.; Dai, H. Ballistic carbon nanotube field-effect transistors. Nature 2003, 424, 654-657. [CrossRef]

25. Li, C.; Zhou, X.; Zhai, F.; Li, Z.; Yao, F.; Qiao, R.; Chen, K.; Yu, D.; Sun, Z.; Liu, K.; et al. Quiver-quenched optical-field-emission from carbon nanotubes. Appl. Phys. Lett. 2017, 111, 133101. [CrossRef]

26. Gobin, A.M.; Lee, M.H.; Halas, N.J.; James, W.D.; Drezek, R.A.; West, J.L. Near-Infrared Resonant Nanoshells for Combined Optical Imaging and Photothermal Cancer Therapy. Nano Lett. 2007, 7, 1929-1934. [CrossRef] [PubMed]

27. Grabtchak, S.; Tonkopi, E.; Whelan, W.M. Optical detection of gold nanoparticles in a prostate-shaped porcine phantom. J. Biomed. Opt. 2013, 18, 077005. [CrossRef] [PubMed]

28. Hikavyy, A.; Clauws, P.; Deferme, W.; Bogdan, G.; Haenen, K.; Nesladek, M. Investigation of hydrogenated CVD diamond films by photo-thermal ionization spectroscopy. Diam. Relat. Mater. 2006, 15, 682-686. [CrossRef]

29. Hobbs, R.G.; Yang, Y.; Fallahi, A.; Keathley, P.D.; de Leo, E.; Kartner, F.X.; Graves, W.; Berggren, K.K. High-Yield, Ultrafast, SurfacePlasmonEnhanced, Au Nanorod Optical Field Electron Emitter Arrays. ACS Nano 2014, 8, 11474-11482. [CrossRef] [PubMed]

30. Jung, S.M.; Hahn, J.; Jung, H.Y.; Suh, J.S. Clean Carbon Nanotube Field Emitters Aligned Horizontally. Nano Lett. 2006, 6, 1569-1573. [CrossRef]

31. Kim, J.W.; Galanzha, E.I.; Shashkov, E.V.; Moon, H.M.; Zharov, V.P. Golden carbon nanotubes as multimodal photoacoustic and photothermal high-contrast molecular agents. Nat. Nanotechnol. 2009, 4, 688-694. [CrossRef]

32. Li, C.C.; Yin, X.M.; Chen, L.B.; Li, Q.H.; Wang, T.H. High capacity and excellent cycling stability of branched cobalt oxide nanowires as Liinsertion materials. Appl. Phys. Lett. 2010, 97, 043501. [CrossRef]

33. Westover, T.L.; Franklin, A.D.; Cola, B.A.; Fisher, T.S.; Reifenberger, R.G. Photo- and thermionic emission from potassiumintercalated carbon nanotube arrays. J. Vac. Sci. Technol. B 2010, 28, 423-434. [CrossRef]

34. Wisitsora-At, A.; Hsu, S.H.; Kang, W.P.; Davidson, J.L.; Tuantranont, A. Advanced nanodiamond emitter with pyramidal tip-on-pole structure for emission self-regulation. J. Vac. Sci. Technol. B 2012, 30, 022204. [CrossRef]

35. Kusunoki, T.; Hashizume, T.; Kasuya, K.; Arai, N. Stabilization of cold-field-emission current from a CeB6 single-crystal emitter by using a faceted (100) plane. J. Vac. Sci. Technol. B 2020, 39, 013202. [CrossRef]

36. Dusane, P.R.; Gavhane, D.S.; Kolhe, P.S.; Bankar, P.K.; Thombare, B.R.; Lole, G.S.; Kale, B.B.; More, M.A.; Patil, S.I. Controlled decoration of palladium $(\mathrm{Pd})$ nanoparticles on graphene nanosheets and its superior field emission behavior. Mater. Res. Bull. 2021, 140, 111335. [CrossRef]

37. Musumeci, P.; Cultrera, L.; Ferrario, M.; Filippetto, D.; Gatti, G.; Gutierrez, M.S.; Moody, J.T.; Moore, N.; Rosenzweig, C.M.S.J.B.; Travish, G.; et al. Multiphoton Photoemission from a Copper Cathode Illuminated by Ultrashort Laser Pulses in an rf Photoinjector. Phys. Rev. Lett. 2010, 104, 084801. [CrossRef]

38. Hommelhoff, P.; Sortais, Y.; Aghajani-Talesh, A.; Kasevich, M.A. Field emission tip as a nanometer source of free electron femtosecond pulses. Phys. Rev. Lett. 2006, 96, 077401. [CrossRef]

39. Li, Y.; Kim, W.; Zhang, Y.; Rolandi, M.; Wang, D.; Dai, H. Growth of Single-Walled Carbon Nanotubes from Discrete Catalytic Nanoparticles of Various Sizes. J. Phys. Chem. B 2001, 105, 11424-11431. [CrossRef]

40. Valfells, A.; Feldman, D.W.; Virgo, M.; O'Shea, P.G.; Lau, Y.Y. Effects of pulse-length and emitter area on virtual cathode formation in electron guns. Phys. Plasmas 2002, 9, 2377-2382. [CrossRef] 
41. Jensen, K.L. Electron emission theory and its application Fowler-Nordheim equation and beyond. J. Vac. Sci. Technol. B 2003, 21, 1528-1544. [CrossRef]

42. Fowler, R.H. The Analysis of Photoelectric Sensitivity Curves for Clean Metals at Various Temperatures. Phys. Rev. 1931, 38, 45-56. [CrossRef]

43. Fann, W.S.; Storz, R.; Tom, H.W.; Bokor, J. Electron thermalization in gold. Phys. Rev. B Condens Matter 1992, 46, 13592-13595. [CrossRef]

44. Barwick, B.; Corder, C.; Strohaber, J.; Chandler-Smith, N.; Uiterwaal, C.; Batelaan, H. Laser-induced ultrafast electron emission from a field emission tip. New J. Phys. 2007, 9, 142. [CrossRef]

45. DuBridge, L.A. Theory of the Energy Distribution of Photoelectrons. Phys. Rev. 1933, 43, 727-741. [CrossRef]

46. Zhou, S.; Chen, K.; Cole, M.T.; Li, Z.; Chen, J.; Li, C.; Dai, Q. Ultrafast Field-Emission Electron Sources Based on Nanomaterials. Adv. Mater. 2019, 31, e1805845. [CrossRef]

47. Li, C.; Zhou, X.; Zhai, F.; Li, Z.; Yao, F.; Qiao, R.; Chen, K.; Cole, M.T.; Yu, D.; Sun, Z.; et al. Carbon Nanotubes as an Ultrafast Emitter with a Narrow Energy Spread at Optical Frequency. Adv. Mater. 2017, 29, 1701580. [CrossRef]

48. Riffe, D.M.; Wang, X.Y.; Downer, M.C.; Fisher, D.L.; Tajima, T.; Erskine, J.L. Femtosecond thermionic emission from metals in the space-charge-limited regim. J. Opt. Soc. Am. B 1993, 10, 1424-1435. [CrossRef]

49. Merschdorf, M.; Pfeiffer, W.; Voll, S.; Gerber, G. Electron gas cooling in Ag nanoparticles on graphite. Phys. Rev. B 2003, 68, 155416. [CrossRef]

50. Hagmann, M.J. Carbon nanotube clusters may give greater output power with large tunable bandwidth from photomixing in laser-assisted field emission. In Proceedings of the 2007 IEEE 20th International Vacuum Nanoelectronics Conference, Chicago, IL, USA, 8-12 July 2007; pp. 50-51. 